\title{
Comparative Efficacy of Irbesartan/ Hydrochlorothiazide and Valsartan/Hydrochlorothiazide Combination in Lowering Blood Pressure: A Retrospective Observational Study in Oman
}

\author{
K.A. Al Balushi $\quad$ J.Q. Habib ${ }^{a} \quad$ I. Al-Zakwani ${ }^{a}$ b \\ ${ }^{a}$ Department of Pharmacology and Clinical Pharmacy, College of Medicine and Health Sciences, Sultan Qaboos \\ University, Al-Khod, and ${ }^{\mathrm{b}}$ Gulf Health Research, Muscat, Oman
}

\section{Key Words}

Irbesartan • Valsartan $\cdot$ Hypertension · Diabetes mellitus • Nephropathy

\begin{abstract}
Objective: To compare blood pressure (BP) control in patients receiving irbesartan/hydrochlorothiazide (HCTZ) and valsartan/HCTZ at a tertiary care university hospital in Oman. Subjects and Methods: This was a retrospective observational study, where 232 patients' medical records were reviewed during a 3-month period, July to September 2010, at Sultan Qaboos University Hospital in Oman. BP readings of the previous 6 months were also retrieved from the electronic medical records. Analyses were conducted using univariate statistical techniques. Results: The mean age of the cohort was $58 \pm 11$ years (range: 21-88). Sixty-nine (30\%) patients were on the irbesartan/HCTZ combination (150/12.5 $\mathrm{mg})$ and $163(70 \%)$ were on the valsartan/HCTZ combination. The patients on the valsartan/HCTZ combination were divided into two subgroups: 117 (72\%) received 160/12.5 mg and $46(28 \%) 80 / 12.5 \mathrm{mg}$. Diabetic patients $(43 / 69,62 \%$, vs. $61 / 163,37 \%, p<0.001$ ) and those with diabetic nephropathy $(8 / 69,12 \%$, vs. $7 / 163,4 \%, p=0.039)$ were prescribed more often irbesartan/HCTZ than valsartan/HCTZ. In comparison to the valsartan/HCTZ cohort, the irbesartan/HCTZ group
\end{abstract}

\section{KARGER}

E-Mail karger@karger.com www.karger.com/mpp

\section{(C) 2012 S. Karger AG, Basel} 1011-7571/13/0223-0265\$38.00/0

Karge

Open access

This is an Open Access article licensed under the terms of the Creative Commons Attribution-NonCommercial-NoDerivs 3.0 License (www.karger.com/OA-license), applicable to the online version of the article only. Distribution for non-commercial purposes only. was associated with significant reductions in both systolic BP (SBP; -9 vs. $-2 \mathrm{~mm} \mathrm{Hg} ; \mathrm{p}=0.021$ ) and diastolic BP (DBP; -5 vs. $0 \mathrm{~mm} \mathrm{Hg} ; \mathrm{p}=0.022$ ). $\mathrm{BP}$ reductions were noted more in diabetics than nondiabetics with the irbesartan/HCTZ patients associated with significant reductions in both SBP ( -12 vs. 5.1 $\mathrm{mm} \mathrm{Hg} ; \mathrm{p}<0.001)$ and DBP (-6.4 vs. $1.9 \mathrm{~mm} \mathrm{Hg} ; \mathrm{p}=0.001)$. Conclusions: The irbesartan/HCTZ combination was associated with significant reductions in both SBP and DBP when compared with the valsartan/HCTZ combination. Specifical$l y$, the reductions were noted more in diabetics than nondiabetics.

Copyright $\odot 2012$ S. Karger AG, Basel

\section{Introduction}

Hypertension is a chronic progressive cardiovascular disorder that affects about $26 \%$ of all adults worldwide [1]. Progression of hypertension leads to abnormalities in cardiac and vascular functions as well as structural damage to the heart, kidneys, brain, vasculature, and other organs, consequently leading to premature morbidity and death $[2,3]$. Hypertension is diagnosed and treated at the threshold blood pressure (BP) levels of $<140 / 90$ and $<130 / 85 \mathrm{~mm}-\mathrm{Hg}$ in nondiabetic and diabetic patients, respectively [4]. Several classes of drugs are used to treat 
hypertension by targeting different aspects of its pathophysiology. Some of the drugs are used as monotherapy while others are used in combination. It is estimated that more than two thirds of hypertensive subjects are not controlled on one drug alone and will thus require two or more antihypertensive agents selected from different drug classes to provide optimum control [4].

Angiotensin II receptor blockers (ARBs) are an effective antihypertensive option with renal and cardioprotective effects coupled with lower adverse effect profile [5]. ARBs differ in pharmacodynamic and pharmacokinetic properties, which may translate into significant differences in their relative antihypertensive potency. ARBs are also available in fixed-dose combination with other antihypertensive drugs such as thiazide diuretics and calcium channel blockers. Valsartan is a potent ARB that has a good BP-lowering effect at doses of 80-320 mg [6]. It is also indicated for heart failure and postmyocardial infarction to reduce cardiovascular mortality [7]. Irbesartan is another ARB prescribed at doses from 75 to 300 $\mathrm{mg}$. It is also approved for the treatment of hypertension. In some countries, irbesartan has been approved for the treatment of nephropathy in patients with hypertension and type 2 diabetes mellitus $[8,9]$. There are currently only a few published studies $[10,11]$ on the comparison of irbesartan/hydrochlorothiazide (HCTZ) and valsartan/ HCTZ combinations with respect to BP control. Therefore, the aim of this study was to compare the effectiveness of irbesartan/HCTZ and valsartan/HCTZ with respect to BP in patients with mild to moderate hypertension at Sultan Qaboos University Hospital, in Muscat, Oman.

\section{Subjects and Methods}

This was a retrospective observational study where the electronic medical records of 232 adult patients ( $\geq 18$ years) who were prescribed irbesartan/HCTZ or valsartan/HCTZ and diagnosed with mild to moderate hypertension were reviewed in a 3-month period between July and September, 2010. The study took place at Sultan Qaboos University Hospital, which is a nearly 600-bed tertiary-care university hospital in Muscat, Oman. Each patient's BP readings were retrieved from the medical records for the previous 6 months prior to the index date. Patients were excluded if they did not have a diagnosis of mild to moderate hypertension. Furthermore, they also had to contribute at least two BP readings (one reading in the index period, July to September 2010, and the other BP reading in the preindex 6 -month period). Patients were also excluded if they were not on the two study medications throughout the study period. Arterial BP was measured by a trained nurse using an oscillometric automatic BP monitor and by a physician using a calibrated standard sphygmomanometer of the appropri- ate cuff size. All BP measurements were taken after the patient had rested in a sitting position for $5 \mathrm{~min}$.

Apart from the BP readings, the study also captured the following variables: age, weight, height, gender (male, female), nationality (Omani, non-Omani), other comorbidities (diabetes mellitus, dyslipidemia, ischemic heart disease, congestive heart failure, stroke, myocardial infarction, atrial fibrillation, anemia, obesity, diabetic nephropathy, diabetic retinopathy, and deep vein thrombosis), and other antihypertensive medications. Ethical approval for the study was obtained from the Ethics Review Committee of the College of Medicine and Health Sciences, Sultan Qaboos University, Muscat, Oman. The study was part of an MSc project for the second author (J.Q.), who did all the data collection while analyses were shared between all the authors.

\section{Power Analysis}

At least 6 months' follow-up on 177 patients were needed (118 on the valsartan group and 59 on the irbesartan group; 1:1/2 ratio, based on prevalence of prescribing) to have $80 \%$ power to detect a difference of $10 \mathrm{~mm} \mathrm{Hg}$ of BP difference (systolic or diastolic) between the two cohorts at the 5\% alpha (significance) level. Because of missing data, additional data were retrieved for 55 subjects for a total of 232 (study sample).

\section{Statistical Analysis}

Descriptive statistics were used to describe the data. For categorical variables, frequencies and percentages were reported. Differences between groups were analyzed using Pearson's $\chi^{2}$ tests (or Fisher's exact tests for cells less than 5). For continuous variables, mean and standard deviation were used to present the data while analysis was performed using Student's t test or paired t test, wherever appropriate. An a priori two-tailed level of significance was set at the 0.05 level. Statistical analyses were conducted using STATA version 12.1 (STATA Corp., College Station, Tex., USA).

\section{Results}

The demographic characteristics of the study sample are summarized in table 1 . Of the 232 patients whose data were obtained from medical records, 69 (30\%) and 163 (70\%) were on irbesartan/HCTZ and valsartan/HCTZ combinations, respectively. For those on irbesartan/ HCTZ, the dose was $150 / 12.5 \mathrm{mg}$, while for those on the valsartan/HCTZ combination, 118 (72\%) were on the $160 / 12.5 \mathrm{mg}$ strength while the remaining 45 (28\%) were on the lower strength, $80 / 12.5 \mathrm{mg}$. The overall mean age of the cohort was $58 \pm 11$ years (range: $21-88$ ); 113 (49\%) subjects receiving the irbesartan/HCTZ and valsartan/ HCTZ combinations were males and 220 (95\%) were Omanis. There were no significant differences in age (60 vs. 58 years; $\mathrm{p}=0.134$ ), gender ( 51 vs. $48 \%$ male; $\mathrm{p}=$ 0.689 ), Omani nationality ( 97 vs. $94 \% ; \mathrm{p}=0.309$ ), and weight ( 80 vs. $79 \mathrm{~kg} ; \mathrm{p}=0.568$ ) among the groups. 
Table 1. Demographic characteristics of the study sample $(\mathrm{n}=$ 232)

\begin{tabular}{llrrr}
\hline $\begin{array}{l}\text { Demographic } \\
\text { characteristics }\end{array}$ & $\begin{array}{l}\text { Irbesartan/ } \\
\text { HCTZ } \\
(\mathrm{n}=69)\end{array}$ & $\begin{array}{l}\text { Valsartan/ } \\
\text { HCTZ } \\
(\mathrm{n}=163)\end{array}$ & $\begin{array}{l}\text { All } \\
(\mathrm{n}=232)\end{array}$ & $\begin{array}{l}\mathrm{p} \\
\text { value }\end{array}$ \\
\hline Mean age $\pm \mathrm{SD}$, years & $60 \pm 11$ & $58 \pm 11$ & $58 \pm 11$ & 0.134 \\
Male gender, $\mathrm{n}(\%)$ & $35(51)$ & $78(48)$ & $113(49)$ & 0.689 \\
$\begin{array}{l}\text { Omani national, } \mathrm{n}(\%) \\
\text { Mean weight } \pm \mathrm{SD}, \mathrm{kg}\end{array}$ & $80 \pm 18$ & $79 \pm 18$ & $79 \pm 18$ & 0.568 \\
\hline
\end{tabular}

$\mathrm{SD}=$ Standard deviation

Table 2. Clinical characteristics of the study cohort $(\mathrm{n}=232)$

\begin{tabular}{lcccr}
\hline Clinical characteristics & $\begin{array}{l}\text { Irbesartan/ } \\
\text { HCTZ } \\
(\mathrm{n}=69)\end{array}$ & $\begin{array}{l}\text { Valsartan/ } \\
\text { HCTZ } \\
(\mathrm{n}=163)\end{array}$ & $\begin{array}{l}\text { All } \\
(\mathrm{n}=232)\end{array}$ & $\begin{array}{l}\mathrm{p} \\
\text { value }\end{array}$ \\
\hline Diabetes mellitus & $43(62)$ & $61(37)$ & $104(45)$ & $<0.001$ \\
Ischemic heart disease & $14(20)$ & $24(15)$ & $38(16)$ & 0.295 \\
Obesity & $7(10)$ & $9(6)$ & $16(7)$ & 0.204 \\
Nephropathy & $8(12)$ & $7(4)$ & $15(6.5)$ & 0.039 \\
Myocardial infarction & $1(1.5)$ & $8(4.9)$ & $9(3.9)$ & 0.287 \\
Chronic heart failure & $1(1.5)$ & $4(4.5)$ & $5(2.2)$ & 1.000 \\
Stroke & $1(1.5)$ & $3(1.8)$ & $4(1.7)$ & 1.000 \\
Atrial fibrillation & $2(2.9)$ & $2(1.2)$ & $4(1.7)$ & 0.584 \\
Anemia & $1(1.5)$ & $2(1.2)$ & $3(1.3)$ & 1.000 \\
Retinopathy & $0(0)$ & $1(0.6)$ & $1(0.4)$ & 1.000 \\
Deep vein thrombosis & $0(0)$ & $1(0.6)$ & $1(0.4)$ & 1.000 \\
\hline & 78 & 122 & 200 & \\
\hline
\end{tabular}

Figures in parentheses indicate column percentages.

They might not add up to $100 \%$ because some patients had more than one comorbidity.

The clinical characteristics of the study cohort are summarized in table 2. Diabetic patients were prescribed irbesartan/HCTZ more than valsartan/HCTZ (62 vs. $37 \%$; $<0.001)$. The three other most frequent comorbid conditions included ischemic heart disease: $16 \%$, obesity: $7 \%$, and nephropathy: $6.5 \%$. Patients with nephropathy were prescribed more irbesartan/HCTZ than valsartan/ HCTZ (12 vs. $4 \% ; \mathrm{p}=0.039$ ). As shown in table 3, there were no significant differences in postindex BP measurements in either systolic BP (SBP; 144 vs. $142 \mathrm{~mm} \mathrm{Hg}$; $=$ 0.618) or diastolic BP (DBP; 76 vs. $77 \mathrm{~mm} \mathrm{Hg}$; $=0.574$ ) between the two cohorts. However, as compared to the valsartan/HCTZ cohort, the irbesartan/HCTZ group was associated with significant reductions in both SBP
( -9 vs. $-2 \mathrm{~mm} \mathrm{Hg}$; $\mathrm{p}=0.021)$ and DBP ( -5 vs. $0 \mathrm{~mm} \mathrm{Hg}$; $\mathrm{p}=0.022)$. When stratified by diabetes mellitus, BP reductions were noted more in diabetics than nondiabetics. In diabetic patients, the irbesartan/HCTZ group was associated with more significant reductions in both SBP $(-12$ vs. $5.1 \mathrm{~mm} \mathrm{Hg}$; p < 0.001) and DBP (-6.4 vs. $1.9 \mathrm{~mm}$ $\mathrm{Hg} ; \mathrm{p}=0.001)$. This significant difference was not apparent in nondiabetic patients ( $p>0.05$, table 3 ).

\section{Discussion}

This study showed that the irbesartan/HCTZ combination was associated with greater reductions in both SBP and DBP when compared with the valsartan/HCTZ combination. Specifically, the reductions were noted more in diabetics than nondiabetics. The study also showed that diabetic and hypertensive patients with nephropathy were more likely to be prescribed the irbesartan/HCTZ than valsartan/HCTZ combination.

It should be noted that patients were also on other antihypertensive medications (78\% irbesartan/HCTZ vs. $69 \%$ valsartan/HCTZ). The cohort receiving the irbesartan/HCTZ combination had also more comorbid conditions compared to the valsartan/HCTZ cohort, especially diabetes mellitus and nephropathy, which could complicate the treatment of hypertension. However, the utilization of other antihypertensive medications was not significantly different between the two cohorts (78 vs. $69 \% ; \mathrm{p}=0.147$, table 4$)$. It is known from major published clinical trials that ARBs are among the drugs of choice in hypertensive patients with diabetes, chronic renal failure or heart failure $[4,12]$. Irbesartan/HCTZ fixed-dose combination is approved in the US for the treatment of patients who are not adequately controlled with irbesartan or HCTZ alone and in patients likely to require multiple drugs to reach target BP [12-14].

The efficacy of irbesartan and valsartan alone or in combination with HCTZ has been explored in several previous studies $[10,11,15]$. A recent post hoc analysis showed that the reduction in home SBP and DBP was numerically greater with irbesartan/HCTZ (150/12.5 $\mathrm{mg})$ compared to valsartan/HCTZ $(80 / 12.5 \mathrm{mg})$ for all subgroups (the difference in DBP was significant for all except the elderly, $\mathrm{p}<0.05$, and the difference in SBP was significant in the elderly and in men, $\mathrm{p}=0.03$ ) [14]. Another 8-week randomized study of 426 patients with mild to moderate hypertension showed that irbesartan $150 \mathrm{mg}$ once daily was associated with superior 24 -hour ambulatory BP control to valsartan $80 \mathrm{mg}$. In addition, 
Table 3. Mean $( \pm S D)$ BP differences of the study cohort $(n=232)$

\begin{tabular}{|c|c|c|c|c|}
\hline Blood pressure measurements & $\begin{array}{l}\text { Irbesartan/HCTZ } \\
(\mathrm{n}=69)\end{array}$ & $\begin{array}{l}\text { Valsartan/HCTZ } \\
(\mathrm{n}=163)\end{array}$ & $\begin{array}{l}\text { All } \\
(\mathrm{n}=232)\end{array}$ & $\mathrm{p}$ value \\
\hline Pre SBP, mm Hg & $153 \pm 21$ & $144 \pm 19$ & $146 \pm 20$ & 0.004 \\
\hline Post SBP, mm Hg & $144 \pm 20$ & $142 \pm 22$ & $142 \pm 22$ & 0.618 \\
\hline Post DBP, mm Hg & $76 \pm 12$ & $77 \pm 13$ & $77 \pm 12$ & 0.574 \\
\hline SBP post - SBP pre (difference in SBP) & $-9 \pm 21$ & $-2 \pm 23$ & $-4 \pm 23$ & 0.021 \\
\hline \multicolumn{5}{|l|}{ Diabetic patients $(\mathrm{n}=104)$} \\
\hline Difference in SBP & $-12 \pm 19$ & $5.1 \pm 25$ & $-1.8 \pm 24$ & $<0.001$ \\
\hline Difference in DBP & $-6.4 \pm 10$ & $1.9 \pm 13$ & $-1.5 \pm 13$ & 0.001 \\
\hline \multicolumn{5}{|l|}{ Nondiabetic patients $(\mathrm{n}=128)$} \\
\hline Difference in SBP & $-5.0 \pm 24$ & $-5.9 \pm 22$ & $-5.7 \pm 22$ & 0.859 \\
\hline Difference in DBP & $-2.0 \pm 17$ & $-1.6 \pm 13$ & $-1.7 \pm 14$ & 0.897 \\
\hline
\end{tabular}

Pre $=$ Preindex post $=$ postindex

Table 4. Other antihypertensive medications utilized by the study subjects $(n=232)$

\begin{tabular}{lcccc}
\hline & $\begin{array}{l}\text { Irbesartan/HCTZ } \\
(\mathrm{n}=69)\end{array}$ & $\begin{array}{l}\text { Valsartan/HCTZ } \\
(\mathrm{n}=163)\end{array}$ & $\begin{array}{l}\text { All } \\
(\mathrm{n}=232)\end{array}$ & $\mathrm{p}$ value \\
& $15(22)$ & $51(31)$ & $66(28)$ & 0.147 \\
Only ARB with HCTZ & & & \\
Combined with 1 drug (39\%) & $9(13)$ & $24(15)$ & $33(14)$ & 0.839 \\
BB & $13(19)$ & $36(22)$ & $49(21)$ & 0.725 \\
CCB & $2(2.9)$ & $5(3.1)$ & $7(3.0)$ & 1.000 \\
Diuretic & $0(0)$ & $1(0.6)$ & $1(0.4)$ & 1.000 \\
Vasodilator & $16(23)$ & $26(16)$ & $42(18)$ & 0.197 \\
Combined with 2 drugs (28\%) & $4(5.8)$ & $3(1.8)$ & $8(3.0)$ & 0.201 \\
CCB + BB & $2(2.9)$ & $6(3.7)$ & $4(1.7)$ & 1.000 \\
CCB + diuretic & $1(1.5)$ & $3(1.8)$ & $3(1.3)$ & 1.000 \\
BB + diuretic & $2(2.9)$ & $0(0.6)$ & $1(0.4)$ & 0.212 \\
BB + vasodilator & $1(1.5)$ & & $4(1.7)$ & 0.297 \\
CCB + vasodilator & & $3(1.8)$ & $4(1.7)$ & 1.000 \\
Vasodilator + diuretic & $1(1.5)$ & $3(1.8)$ & $2(0.9)$ & 1.000 \\
Combined with $\geq 3$ drugs (5\%) & $1(1.5)$ & $1(0.6)$ & $1(0.4)$ & 0.507 \\
BB + diuretic + vasodilator & $1(1.5)$ & $0(0)$ & & 1.000 \\
BB + CCB + diuretic & $1(1.5)$ & & \\
BB + CCB + vasodilator & & & \\
BB + CCB + vasodilator + diuretic & & & \\
\hline
\end{tabular}

Number of patients with percentages in parentheses.

$\mathrm{BB}=$ Beta-blocker; $\mathrm{CCB}=$ calcium channel blocker.

the proportion of patients who achieved normalized BP (DBP $<90 \mathrm{~mm} \mathrm{Hg}$ ) was significantly greater in the irbesartan group compared to the valsartan group (53 vs. $38 \% ; p=0.004$ ) [15]. Furthermore, the fixed-dose combination of irbesartan/HCTZ (150/12.5 mg) has been shown to achieve significantly superior BP lowering compared with valsartan/HCTZ $(80 / 12.5 \mathrm{mg})$, as assessed by office BP measurements and home BP monitoring in the COSIMA (Comparative Study of Efficacy of Irbesartan/HCZ with Valsartan/HCZ Using Home Blood Pressure Monitoring in the Treatment of Mild to Moderate Hypertension) study [10]. The findings of the 
current study confirmed the results of these earlier studies $[10,11,15]$. However, other studies $[16,17]$ have shown contrasting results. A study found no significant difference between irbesartan $150 \mathrm{mg}$ and valsartan 80 $\mathrm{mg}$ in terms of efficacy of reducing SBP and DBP [16]. Another meta-analysis of randomized controlled trials for treatment of adult hypertension found that irbesar$\tan 150 \mathrm{mg}$ is less effective in reducing SBP and DBP than valsartan $160 \mathrm{mg}$, with differences in the mean change in BP of $3.56 \mathrm{~mm} \mathrm{Hg}(95 \%$ CI: $0.77,6.38)$ and $2.06 \mathrm{~mm} \mathrm{Hg}$ (95\% CI: 0.71, 3.45) [17]. In summary, published studies have demonstrated conflicting comparative efficacy of valsartan and irbesartan regarding $\mathrm{BP}$ control. These conflicting results could have been attributed to differences in methodologies including samples sizes and patient case-mix as well as differential doses of irbesartan and valsartan and combination therapies with HCTZ.
The limitations of this study include its retrospective nature. A significant proportion of patients had missing data on baseline BP readings and hence were excluded. This could also have affected the results. However, the fact that all patients that met the inclusion criteria over the 3-month period were captured without exception, this is likely to have minimized any biases.

\section{Conclusions}

The irbesartan/HCTZ combination was associated with significant reductions in $\mathrm{BP}$ when compared to the valsartan/HCTZ combination. The reductions were associated mainly in diabetics and patients with diabetic nephropathy. Thus, a significant implication of this study is that the irbesartan/HCTZ combination could be an appropriate therapy for patients with hypertension and diabetes.

\section{References}

-1 Kearney PM, Whelton M, Reynolds K, Muntner P, Whelton PK, He J: Global burden of hypertension: analysis of worldwide data. Lancet 2005;365:217-223.

$\checkmark 2$ Giles TD, Berk BC, Black HR, Cohn JN, Kostis JB, Izzo JL Jr, Weber MA: Expanding the definition and classification of hypertension. J Clin Hypertens (Greenwich) 2005; 505-512.

3 Zappe D, Papst CC, Ferber P: Randomized study to compare valsartan \pm HCTZ versus amlodipine \pm HCTZ strategies to maximize blood pressure control. Vasc Health Risk Manag 2009;5:883-892.

4 Chobanian AV, Bakris GL, Black HR, Cushman WC, Green LA, Izzo JL Jr, et al: Seventh report of the Joint National Committee on Prevention, Detection, Evaluation, and Treatment of High Blood Pressure. Hypertension 2003;42:1206-1252.

5 Treat Guidel Med Lett 2009;7:77. Retrieved February 15, 2010 from http://www. medicalletter.org/
-6 Malacco E, Santonastaso M, Vari NA, Gargiulo A, Spagnuolo V, Bertocchi F, et al: Comparison of valsartan $160 \mathrm{mg}$ with lisinopril $20 \mathrm{mg}$, given as monotherapy or in combination with a diuretic, for the treatment of hypertension: the blood pressure reduction and tolerability of valsartan in comparison with lisinopril (PREVAIL) study. Clin Ther 2004;26:855-865.

7 Black HR, Bailey J, Zappe D, Samuel R: Valsartan more than a decade of experience. Drugs 2009;69:2393-2414.

8 Retrieved from http://www.pslgroup.com/ dg/21DFFE.htm

$\checkmark 9$ Croom KF, Plosker GL: Irbesartan: a review of its use in hypertension and diabetic nephropathy. Drugs 2008;68:1543-1569.

10 Asmar R, Oparil S: Comparison of the antihypertensive efficacy of irbesartan/HCTZ and valsartan/HCTZ combination therapy: impact of age and gender. Clin Exp Hypertens 2010;32:499-503.

-11 Bobrie G, Delonca J, Moulin C, Giacomino A, Postel-Vinay N, Asmar R: A home blood pressure monitoring study comparing the antihypertensive efficacy of two angiotensin II receptor antagonist fixed combinations. Am J Hypertens 2005;18:1482-1488.
-12 American Diabetes Association: Standards of medical care in diabetes. Diabetes Care 2008;31:S12-S54.

13 Avalide prescribing information. 2007. Retrieved from http://www.avapro-avalide. com/pi_pop.aspx

14 Struthers AD, McMurray JJ: The place of angiotensin-converting enzyme inhibitors in internal medicine. Med Princ Pract 1989;1: 65-70.

15 Malacco E, Piazza S, Meroni R, Milanesi A: Comparison of valsartan and irbesartan in the treatment of mild to moderate hypertension: a randomized, open-label, crossover study. Curr Ther Res Clin Exp 2000;61:789797.

-16 Mancia G, Korlipara K, van Rossum P, Villa G, Silvert B: An ambulatory blood pressure monitoring study of the comparative antihypertensive efficacy of two angiotensin II receptor antagonists, irbesartan and valsartan. Blood Press Monit 2002;7:135-142.

17 Nixon RM, Müller E, Lowy A, Falvey H: Valsartan vs. other angiotensin II receptor blockers in the treatment of hypertension: a meta-analytical approach. Int J Clin Pract 2009;63:766-775. 